\title{
The mitochondrial genome of the chimpanzee louse, Pediculus schaeffi: insights into the process of mitochondrial genome fragmentation in the blood-sucking lice of great apes
}

\author{
Kate E. Herd ${ }^{1}$, Stephen C. Barker ${ }^{1}$ and Renfu Shao ${ }^{2^{*}}$
}

\begin{abstract}
Background: Blood-sucking lice in the genera Pediculus and Pthirus are obligate ectoparasites of great apes. Unlike most bilateral animals, which have 37 mitochondrial (mt) genes on a single circular chromosome, the sucking lice of humans have extensively fragmented $\mathrm{mt}$ genomes. The head louse, Pediculus capitis, and the body louse, Pe. humanus, have their $37 \mathrm{mt}$ genes on 20 minichromosomes. The pubic louse, Pthirus pubis, has its $34 \mathrm{mt}$ genes known on 14 minichromosomes. To understand the process of $\mathrm{mt}$ genome fragmentation in the sucking lice of great apes, we sequenced the mt genome of the chimpanzee louse, Pe. schaeffi, and compared it with the three human lice.
\end{abstract}

Results: We identified all of the $37 \mathrm{mt}$ genes typical of bilateral animals in the chimpanzee louse; these genes are on 18 types of minichromosomes. Seventeen of the 18 minichromosomes of the chimpanzee louse have the same gene content and gene arrangement as their counterparts in the human head louse and the human body louse. However, five genes, cob, $\operatorname{trn} S_{1}, \operatorname{trnN}$, trnE and $\operatorname{trn} M$, which are on three minichromosomes in the human head louse and the human body louse, are together on one minichromosome in the chimpanzee louse.

Conclusions: Using the human pubic louse, Pt. pubis, as an outgroup for comparison, we infer that a single minichromosome has fragmented into three in the lineage leading to the human head louse and the human body louse since this lineage diverged from the chimpanzee louse $\sim 6$ million years ago. Our results provide insights into the process of $\mathrm{mt}$ genome fragmentation in the sucking lice in a relatively fine evolutionary scale.

Keywords: Chimpanzee louse, Pediculus schaeffi, Mitochondrial genome, Minichromosomes

\section{Background}

The closest extant relatives of humans are chimpanzees (bonobos and common chimpanzees) and gorillas. Humans share a common ancestor with gorillas, Gorilla gorilla and G. beringei, $\sim 7$ million years ago (MYA) and share a common ancestor with chimpanzees, Pan troglodytes and Pan paniscus, 6 MYA ([1, 2], but see [3-5] for variation of the divergence time estimates). Due to the close evolutionary relationship between humans and these great apes, their parasites are closely related too [6]. All

\footnotetext{
* Correspondence: rshao@usc.edu.au

${ }^{2}$ GeneCology Research Centre, Faculty of Science, Education and Engineering, University of the Sunshine Coast, Maroochydore, QLD, Australia Full list of author information is available at the end of the article
}

great apes, with the exception of orangutans, Pongo pygmaeus, are parasitised by sucking lice (suborder Anoplura) of two genera, Pediculus and Pthirus [7, 8].

Humans are parasitised by three species of lice. Pediculus capitis, the head louse, lives on human head hair and is still prevalent in many countries, particularly in school-aged children. Pe. humanus, the human body louse, lives on human clothes and is thought to have evolved to exploit this new niche when humans began to wear clothing 100,000 to 200,000 years ago [9-11]. Although not as prevalent as the head lice, body lice are healthily more important as they are vectors for three pathogens that cause trench fever, recurrent fever and epidemic typhus in humans [12]. Humans also have the pubic louse, Pthirus 
pubis, which lives on the pubic hair and sometimes eyelashes [13]. The human head louse and the body louse share a genus exclusively with the chimpanzee louse, $P e$. schaeffi, whereas the human pubic louse shares a genus exclusively with the gorilla louse, Pt. gorilla $[7,8,14,15]$.

The mitochondrial $(\mathrm{mt})$ genomes of the three human lice have fragmented extensively. The typical $\mathrm{mt}$ genomes of bilateral animals have 37 genes on a single circular chromosome [16, 17]. The human head louse and the body louse, however, have their $37 \mathrm{mt}$ genes on 20 types of minichromosomes $[18,19]$. The $34 \mathrm{mt}$ genes known of the human pubic louse are on 14 minichromosomes [19]. To understand the process of $\mathrm{mt}$ genome fragmentation in the sucking lice of great apes, we sequenced the $\mathrm{mt}$ genome of the chimpanzee louse, $P e$. schaeffi, and compared it with those of the human lice. We found that the $37 \mathrm{mt}$ genes of the chimpanzee louse are on 18 types of minichromosomes. We show that a single minichromosome has fragmented into three in the lineage leading to the human body louse and head louse since this lineage diverged from the chimpanzee louse $\sim 6$ million years ago. Our results provide insights into the process of $\mathrm{mt}$ genome fragmentation in the sucking lice in a relatively fine evolutionary scale.

\section{Methods}

Collection of lice, DNA extraction, mitochondrial genome amplification and sequencing

Chimpanzee lice, Pe. schaeffi, were collected from rescued wild chimpanzees by staff of the Tacugama Chimpanzee Sanctuary in Sierra Leone (sample No. B2148) and were preserved in $100 \%$ ethanol. No animal ethical approval was required for research on parasitic lice including chimpanzee lice and human lice in Australia. Total cellular DNA was extracted from individual lice using DNeasy Blood and Tissue kit (QIAGEN). A 423-bp fragment of mt cox1 gene and a 503-bp fragment of mt $r r n L$ gene of the chimpanzee lice were amplified initially by PCR with primer pairs mtd7-mtd9a and mtd32m-mtd34Ph (Additional file 1). These primers target conserved sequence motifs in the mt genome of the chimpanzee lice. The $\operatorname{cox} 1$ and $r r n L$ fragments were sequenced directly with AB3730xl 96-capillary sequencers at the Australian Genome Research Facilities (AGRF).

Two pairs of chimpanzee louse specific primers, Pscox1Frev-Pscox1Rrev and P:sh16SF-16SrevP:schaeffi, were designed from cox 1 and $r r n L$ (Additional file 1). PCRs with these chimpanzee louse specific primers amplified the complete cox 1 minichromosome $(\sim 3.3 \mathrm{~kb}$, Additional file $2 \mathrm{~A}$ ) and $L_{2(/ 1)}-r r n L$ minichromosome ( $3.0 \mathrm{~kb}$, Additional file 2B) except a 203-bp and a 231bp gap between the primers, respectively. PCR amplicons from these two minichromosomes were sequenced using a primer-walking strategy with AB3730xl 96- capillary platform at the AGRF (see Additional file 1 for primers used). Sequences of the non-coding regions of the cox 1 minichromosome and $L_{2(/ 1)}-r r n L$ minichromosome were obtained and aligned with ClustalX [20]. A forward primer (PsF) and a reverse primer (PsR) were designed from highly conserved non-coding sequences adjacent to the 5 '-end and the 3 '-end, respectively, of the coding regions (Additional files 1 and 3). The PCR with PsF and PsR produced a mixture of amplicons ranging from 200 to $1800 \mathrm{bp}$ from the coding regions of the mt minichromosomes of the chimpanzee louse (Additional file 2C). Amplicons generated with PsF - PsR were sequenced with a Roche GS FLX platform at the AGRF. To obtain non-coding region sequences, fulllength trnK-nad4 minichromosome and trnL-rrnS-trnC minichromosome were also amplified by PCR with chimpanzee louse specific primers (Additional file 1), and were sequenced together with cox1-minichromosome amplicons using an Illumina Hiseq platform at the Beijing Genomics Institute (BGI).

Takara LA Taq was used in PCR following the manufacturer's protocol. Each PCR $(25 \mu \mathrm{L})$ contained $0.25 \mu \mathrm{L}$ of LA Taq, $2.5 \mu \mathrm{L}$ of $10 \times$ Buffer, $2.5 \mu \mathrm{L}$ of $\mathrm{MgCl}_{2}$ (25 mM), 2.0$4.0 \mu \mathrm{L}$ of dNTP mixture ( $2.5 \mathrm{mM}$ each), $1.0 \mu \mathrm{L}$ of forward primer $(10 \mu \mathrm{M}), 1.0 \mu \mathrm{L}$ of reverse primer $(10 \mu \mathrm{M}), 1.0 \mu \mathrm{L}$ of DNA template, and $12.75-14.75 \mu \mathrm{L}$ of Milli-Q water. Thermal cycling conditions were $94{ }^{\circ} \mathrm{C}$ for $1 \mathrm{~min}$; then 38 cycles of $94{ }^{\circ} \mathrm{C}$ for $30 \mathrm{~s}$; $50-58{ }^{\circ} \mathrm{C}$ (depending on primers) for $30 \mathrm{~s}$; $68{ }^{\circ} \mathrm{C}$ for $1-4 \mathrm{~min}$ (depending on amplicon size); and finally $68{ }^{\circ} \mathrm{C}$ for $2-8 \mathrm{~min}$ (depending on amplicon size). Negative controls were run with each PCR experiment to detect false positive amplicons and DNA contamination. PCR products were checked by agarose gel eletrophoresis (1\%); the sizes of PCR products were estimated by comparing with molecular markers. PCR products were purified using the $\mathrm{Wizard}^{\circledR} \mathrm{SV}$ Gel and PCR Clean-up System (Promega).

\section{Assembly of Roche and Illumina sequence reads and mitochondrial genome annotation}

Raw sequence-reads were assembled de novo using Geneious [21] with the parameters: 1) minimum overlap $150 \mathrm{bp}$ (for Roche reads) and $70 \mathrm{bp}$ (for Illumina reads); 2) minimum overlap identity $95 \%$; 3) maximum $10 \%$ gaps per read; and 4) maximum gap size $10 \mathrm{bp}$. Proteincoding and rRNA genes were identified with BLAST searches (Basic Local Alignment Search Tool) of NCBI database [22] and verified by sequence alignment with their homologous mt genes of the human lice $[18,19]$. tRNA genes were identified with tRNAscan-SE [23], ARWEN [24] and MITOS [25]. Shared identical sequences between genes were identified with Wordmatch [26]. Sequence alignment was made with Clustal X [20]. 


\section{Results and discussion}

The mitochondrial genome of the chimpanzee louse comprises 18 types of minichromosomes

We sequenced the amplicons generated with the primer pair, PsF-PsR, from the chimpanzee louse, Pe. schaeffi, and obtained 24,230 sequence-reads, which range from 150 to 602 bp long. We assembled these sequence-reads into contigs and identified all of the $37 \mathrm{mt}$ genes typical of bilateral animals in the chimpanzee louse; these genes are on 18 types of minichromosomes (Fig. 1; Table 1). Each minichromosome has $1-5$ genes and is 3-4 kb in size, with a coding region, 145 (for trn W-trn $S_{2}$ minichromosome) to $1617 \mathrm{bp}$ (for nad5 minichromosome) in size, and a non-coding region (NCR). Seventeen of the $18 \mathrm{mt}$ minichromosomes of the chimpanzee louse have their counterparts with the same gene content and gene arrangement in the human head louse, Pe. capitis, and the human body louse, Pe. humanus $[18,19]$. Only cob-trn $S_{1}$-trnN-trnEtrnM minichromosome of the chimpanzee louse is not seen in the human head louse and the body louse; the five genes on this minichromosome are on three minichromosomes in the two human lice.
We identified 21 of the $22 \mathrm{mt}$ tRNA genes of the chimpanzee louse with tRNAscan-SE [23], ARWEN [24] and MITOS [25] on the basis of their inferred secondary structures and anticodon sequences (Additional file 4). We could not identify trnD with these programs. Instead, we used the $\operatorname{trn} D$ sequences of the human head louse and the body louse [19] to locate this gene in the chimpanzee louse. $\operatorname{trn} D$ of the chimpanzee louse is on a minichromosome with trnT and trnH and has $72 \%$ sequence similarity to trnD of the human head louse and body louse (Additional file 4). Furthermore, the location of $\operatorname{trn} D$ of the chimpanzee louse relative to their neighbour genes is the same as that in the human head louse and the body louse (Fig. 1) [18, 19].

As in the human lice [19], $\operatorname{trn} L_{1}(\mathrm{tag})$ and $\operatorname{trn} L_{2}(\mathrm{taa})$ of the chimpanzee louse differ by only one nucleotide at the third anticodon position (Additional file 4). Our Roche deep sequencing revealed that both $\operatorname{trn} L_{1}(\mathrm{tag})$ and $\operatorname{trnL}_{2}(\mathrm{taa})$ were present before $r r n S$ and $r r n L$ in the chimpanzee louse: for $r r n S$ the vast majority were $\operatorname{trn} L_{1}$ (94.5\%) whereas for $r r n L$ the vast majority were $\operatorname{trn} L_{2}$ (97.3 \%) (Fig. 1). The relative abundance between the

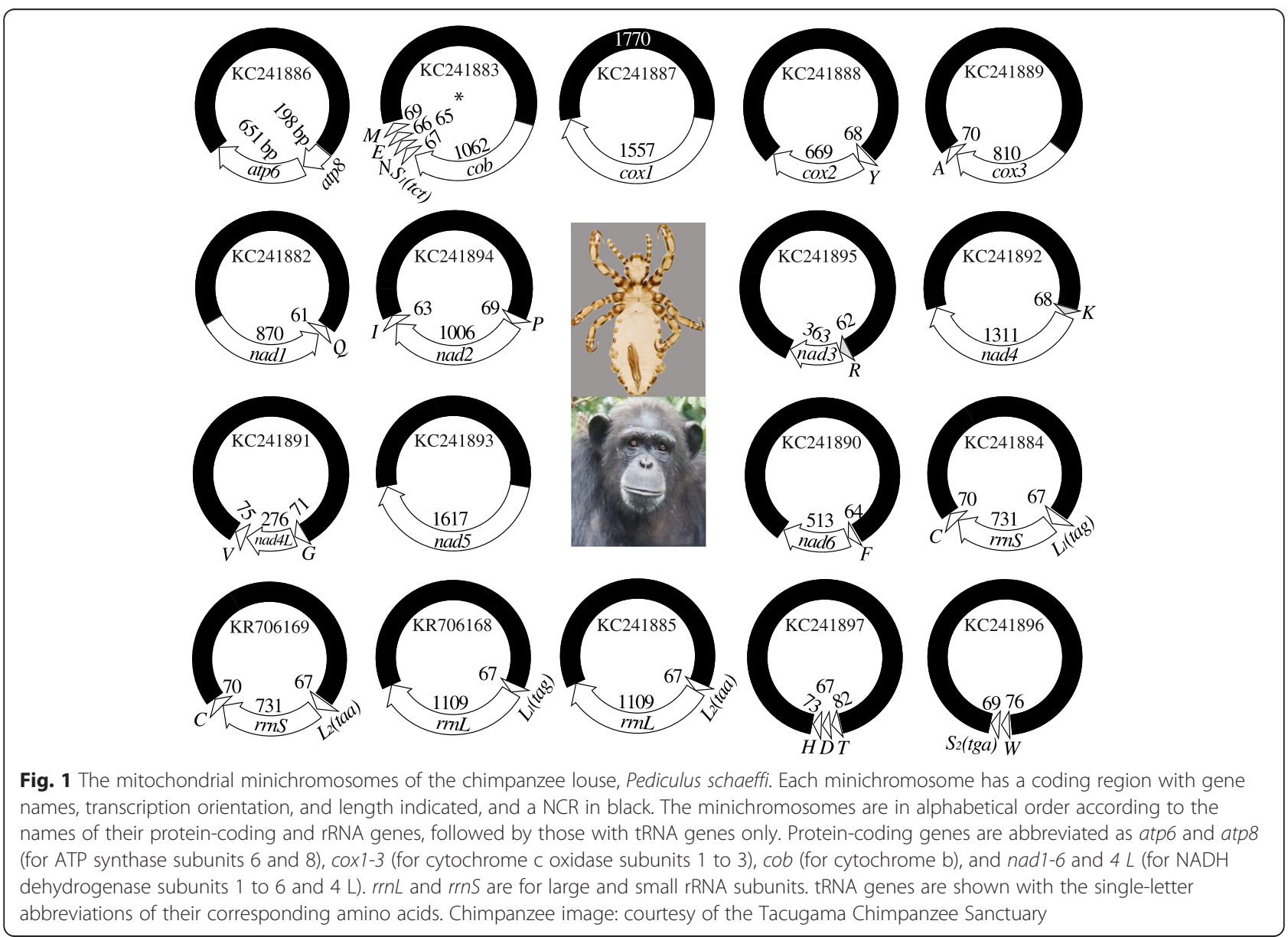


Table 1 Mitochondrial minichromosomes of the chimpanzee louse, Pediculus schaeffi, identified by Roche 454 sequencing

\begin{tabular}{|c|c|c|}
\hline Minichromosome & $\begin{array}{l}\text { Length of coding } \\
\text { region (bp) }\end{array}$ & $\begin{array}{l}\text { Number of Roche } \\
\text { sequence-reads }\end{array}$ \\
\hline atp8-atp6 & 838 & 1372 \\
\hline $\begin{array}{l}\text { cob-trnS1-trnN-trnE- } \\
\text { trnM }\end{array}$ & 1354 & 692 \\
\hline $\operatorname{cox} 1$ & 1557 & 764 \\
\hline $\operatorname{trn} Y-\cos 2$ & 737 & 688 \\
\hline $\operatorname{cox} 3-\operatorname{trn} A$ & 884 & 1357 \\
\hline nad1-trnQ & 964 & 1448 \\
\hline trnP-nad2-trnl & 1138 & 553 \\
\hline trnR-nad3 & 425 & 3433 \\
\hline trnK-nad4 & 1379 & 336 \\
\hline 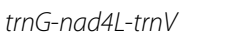 & 420 & 7038 \\
\hline nad5 & 1617 & 158 \\
\hline trnF-nad6 & 573 & 2149 \\
\hline $\operatorname{trn} L_{1(2)}-r r n S-t r n C^{b}$ & 916 & 1628 \\
\hline $\operatorname{trn} L_{2(1)}-r r n L^{c}$ & 1224 & 1263 \\
\hline $\operatorname{trnW} \mathrm{W}-\operatorname{trnS} \mathrm{S}_{2}$ & 145 & 135 \\
\hline $\operatorname{trn} T$-trnD-trnH & 233 & 1216 \\
\hline
\end{tabular}

${ }^{a}$ The number of sequence-reads depended on the assembly parameters; the parameters used here were: minimum overlap $150 \mathrm{bp}$; minimum overlap identity $95 \%$; maximum $10 \%$ gaps per read; and maximum gap size $10 \mathrm{bp}$ ${ }^{\mathrm{b}}$ Both $\operatorname{trn} L_{1}(\operatorname{tag})(94.5 \%)$ and $\operatorname{trn} L_{2}(\operatorname{taa})(5.5 \%)$ were found before $r r n S^{c}{ }^{c}$ both $t^{\prime n} L_{1}(2.7 \%)$ and $t r n L_{2}(97.3 \%)$ were found before $r r n L$ (Additional file 5)

two trnL genes in the four types of minichromosomes that contain $r r n S$ and $r r n L$ genes of the chimpanzee louse was consistent with that of the human head louse and the body louse we investigated (Additional file 5).

We sequenced the full-length NCR of $\operatorname{cox} 1$ minichromosome with an Illumina Hiseq platform; we were unable, however, to sequence a gap downstream the GC-rich motif in the NCR of trnK-nad4 minichromosome, nor trnL-rrnS-trnC minichromosome, although we used the same sequencing strategy. The NCR of $\operatorname{cox} 1$ minichromosome is 1770 bp long with a GC-rich motif and an ATrich motif at two ends that are highly conserved in other minichromosomes. There are two repeat units in the NCR of cox 1 minichromosome, 112 and 114 bp long respectively; these two units are $406 \mathrm{bp}$ apart from one another and have $94 \%$ similarity (Additional file 3 ).

\section{Recombination hot-spots revealed by shared identical sequences between mitochondrial genes in the chimpanzee louse}

Seven stretches of identical nucleotide sequences, 31 to $133 \mathrm{bp}$ long, were found between five pairs of $\mathrm{mt}$ genes in the chimpanzee louse (Table 2). As in the three human lice [19], $\operatorname{trn} L_{1}$ and $\operatorname{trn} L_{2}$ of the chimpanzee louse differ by only one nucleotide at the third anticodon position, and thus share two stretches of identical sequences, 32 and 34 bp respectively (Fig. 2a; Additional file 4). nad5 and $r r n L$ share 101-bp identical sequence in the chimpanzee louse; these two genes share 99-bp identical sequence in the human head louse and the human body louse, but not in the human pubic louse [19], nor in other blood-sucking lice [27]. cox1 and nad3 share 49 bp of identical sequence in the chimpanzee louse; these two genes, however, do not share longer-thanexpected identical sequences in the human lice, nor in other sucking lice. atp 8 and $c o b$ share 26 bp of identical sequence in the human head and body lice but share $54 \mathrm{bp}$ of identical sequence in the chimpanzee louse. nad4 and nad5 share two stretches of identical sequences, 31 and 133 bp long, in the chimpanzee louse; in the human head louse and body louse, these two genes share 30 and 127 bp identical sequences.

Table 2 The longest identical sequences shared by mitochondrial genes of the chimpanzee louse and the human lice, which have fragmented mitochondrial genomes, and six other species of animals, which have typical mitochondrial genomes

\begin{tabular}{|c|c|c|c|c|c|c|c|c|c|c|c|}
\hline \multirow{2}{*}{\multicolumn{2}{|c|}{ Pair of gene }} & \multicolumn{10}{|c|}{ The longest shared identical sequences (bp) } \\
\hline & & \multirow{2}{*}{$\begin{array}{l}P S \\
32,34\end{array}$} & \multirow{2}{*}{$\begin{array}{l}P C \\
32,33\end{array}$} & \multirow{2}{*}{$\begin{array}{l}\mathrm{Ph} \\
32,33\end{array}$} & \multirow{2}{*}{$\begin{array}{l}P p \\
32,35\end{array}$} & \multirow{2}{*}{$\frac{\mathrm{Bm}}{7}$} & \multirow{2}{*}{$\frac{C b}{6}$} & \multirow{2}{*}{$\frac{\mathrm{Hm}}{7}$} & \multirow{2}{*}{$\frac{\text { Dy }}{10}$} & \multirow{2}{*}{$\frac{\mathrm{Ce}}{6}$} & \multirow{2}{*}{$\frac{\mathrm{Hs}}{6}$} \\
\hline $\operatorname{trn} L_{1}$ & $\operatorname{trn} L_{2}$ & & & & & & & & & & \\
\hline $\operatorname{trn} G$ & $\operatorname{trn} R$ & 10 & 14,28 & 14,28 & 26,32 & 5 & 6 & 7 & 6 & 8 & 6 \\
\hline $\operatorname{trn} l$ & $\operatorname{trnT}$ & 7 & 6 & 6 & 16 & 6 & 5 & 7 & 7 & 9 & 6 \\
\hline $\operatorname{cox} 1$ & nad4L & 11 & 10 & 10 & 29 & 13 & 11 & 14 & 13 & 12 & 10 \\
\hline nad5 & $r r n L$ & 101 & 99 & 99 & 10 & 12 & 14 & 13 & 15 & 16 & 10 \\
\hline nad2 & $r r n L$ & 11 & 26 & 26 & 10 & 13 & 11 & 14 & 13 & 12 & 10 \\
\hline $\operatorname{cox} 1$ & nad3 & 49 & 11 & 10 & 11 & 13 & 11 & 12 & 13 & 11 & 12 \\
\hline atp8 & $c o b$ & 54 & 26 & 26 & 9 & 10 & 11 & 11 & 12 & N.A. & 9 \\
\hline nad4 & nad5 & 31,133 & 30,130 & 30,130 & N.A. & 13 & 15 & 15 & 16 & 14 & 11 \\
\hline
\end{tabular}

Shared identical sequences longer than expected by chance are in bold
Ps Pediculus schaeffi (chimpanzee louse), Pc Pediculus capitis (human head louse), Ph Pediculus humanus (human body louse), Pp Pthirus pubis (human pubic louse), $\mathrm{Bm}$ Bothriometopus macrocnemis (screamer louse), Cb Campanulotes bidentatus (pigeon louse), Hm Heterodoxus macropus (wallaby louse), Dy Drosophila yakuba (fruitfly), Ce Caenorhabditis elegans (roundworm), Hs Homo sapiens (human) 
(a)
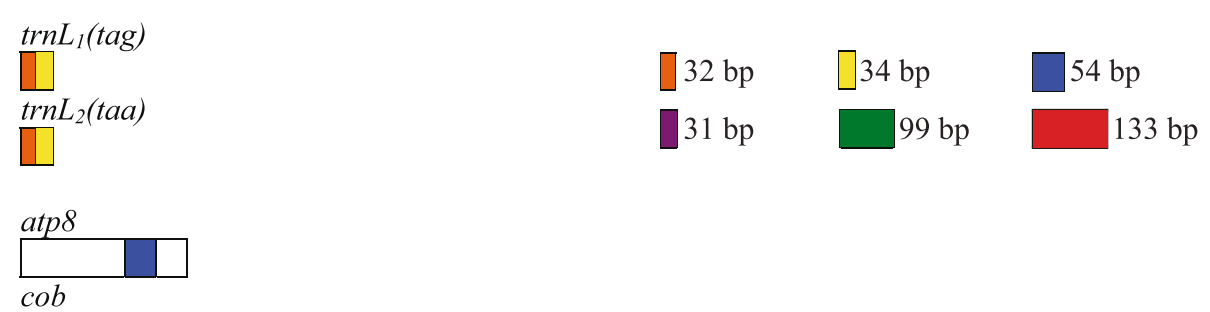

\begin{tabular}{|l|l|l|}
\hline & & \\
\hline
\end{tabular}

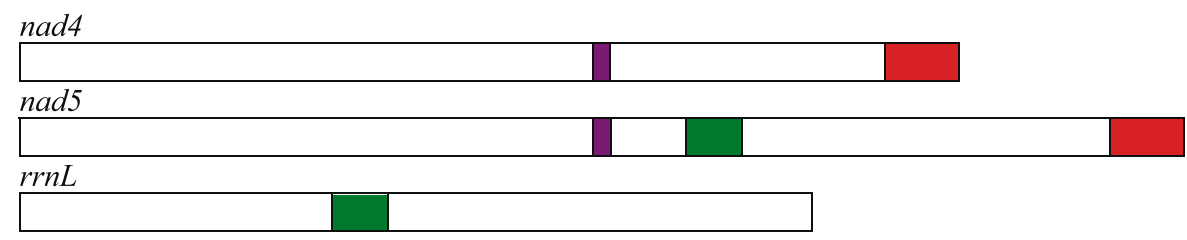

(b)

TTTAGTAGGAAAAGATTAGTCATTTGAGTGTGAGGAGGGTTTTCAGTAAGTCA

$\begin{array}{lllllllllllllllllll}\text { atp8 } & F & S & S & K & S & F & S & H & L & S & V & S & S & V & F & S & K & S\end{array}$

$\begin{array}{lllllllllllllllllllllllllllllllll}c o b & L & V & G & K & D & L & V & I & W & V & W & G & G & F & S & V & S\end{array}$

Fig. 2 Recombination hot-spots in the mitochondrial genomes of the chimpanzee louse, Pediculus schaeffi, indicated by shared identical sequences between non-homologous genes. a: locations of shared identical sequences in genes. Shared identical sequences are highlighted in color with their length in bp. Genes are indicated with boxes from 5' end to 3' end. b: the 56-bp identical sequence shared between atp8 and cob used different open reading frames

The 133-bp identical sequences shared between nad4 and nad5 in the chimp lice are at the 3 ' ends of these two genes. The question arisen was whether or not these sequences were indeed part of nad4 and nad5. We annotate these sequences as part of nad4 and nad5 on the basis that: 1) each of them is part of an open reading frame (ORF); 2) the two ORFs with these sequences included are in the usual, expected length of nad4 and nad5 genes of insects; 3) these sequences are only present in nad4 and nad5, not in any other genes nor noncoding regions in the chimpanzee louse; and 4) these sequences have high similarity with their corresponding regions of nad4 and nad5 in the human lice (Fig. 3).

The longer-than-expected identical sequences shared between $\mathrm{mt}$ genes in the chimpanzee louse provide further evidence for recombination between $\mathrm{mt}$ minichromosomes in the blood-sucking lice [18, 19, 27-30]. Furthermore, with the only exception of the 49-bp identical sequence shared between cox 1 and nad3, which was found only in the chimpanzee louse (Table 2), all of the six other identical sequences shared by different genes in the chimpanzee louse were in similar length, had high similarity and were at the same gene locations as their counterparts in the human head louse and the body louse (Fig. 2a, Fig. 3). Given the chimpanzee louse had a common ancestor with the human head louse and the body louse 6 MYA (see below), the conserved gene locations for the six shared identical sequences are clearly hot spots for homologous recombination between mt genes in the chimpanzee louse, the human head louse and the body louse (Fig. 3).

When two different genes, non-homologous to each other, share a stretch of identical sequence, it begs the question: from which of the two genes did the shared sequence originate? In the human head louse and the body louse, there is insufficient evidence for us to answer this question for any of the nine shared identical sequences $[18,19]$. This is also the case for all of the shared identical sequences observed in the chimpanzee louse except for the 54-bp identical sequence shared between atp 8 and $c o b$ (Table 2). BLAST searches showed that this 54-bp sequence was from a domain of $c o b$ conserved among insects and thus had a $c o b$ origin; intriguingly, this 54-bp sequence used the second open reading frame in $c o b$ but used the first frame in atp 8 (Fig. 2b).

\section{Mitochondrial genome fragmentation in the blood- sucking lice of great apes}

All great apes, with the exception of orangutans are parasitised by sucking lice of the genera Pediculus and Pthrius [7, 8]. The human head louse, Pe. capitis, and the human body louse, Pe. humanus, share a genus exclusively with the chimpanzee louse, Pe. schaeffi, whereas the human pubic louse, Pt. pubis, shares a genus exclusively with the gorilla louse, Pt. gorilla. Two hypotheses have been raised for the distribution of the sucking lice in the genera Pediculus and Pthirus among humans, chimpanzees and gorillas. The first hypothesis 


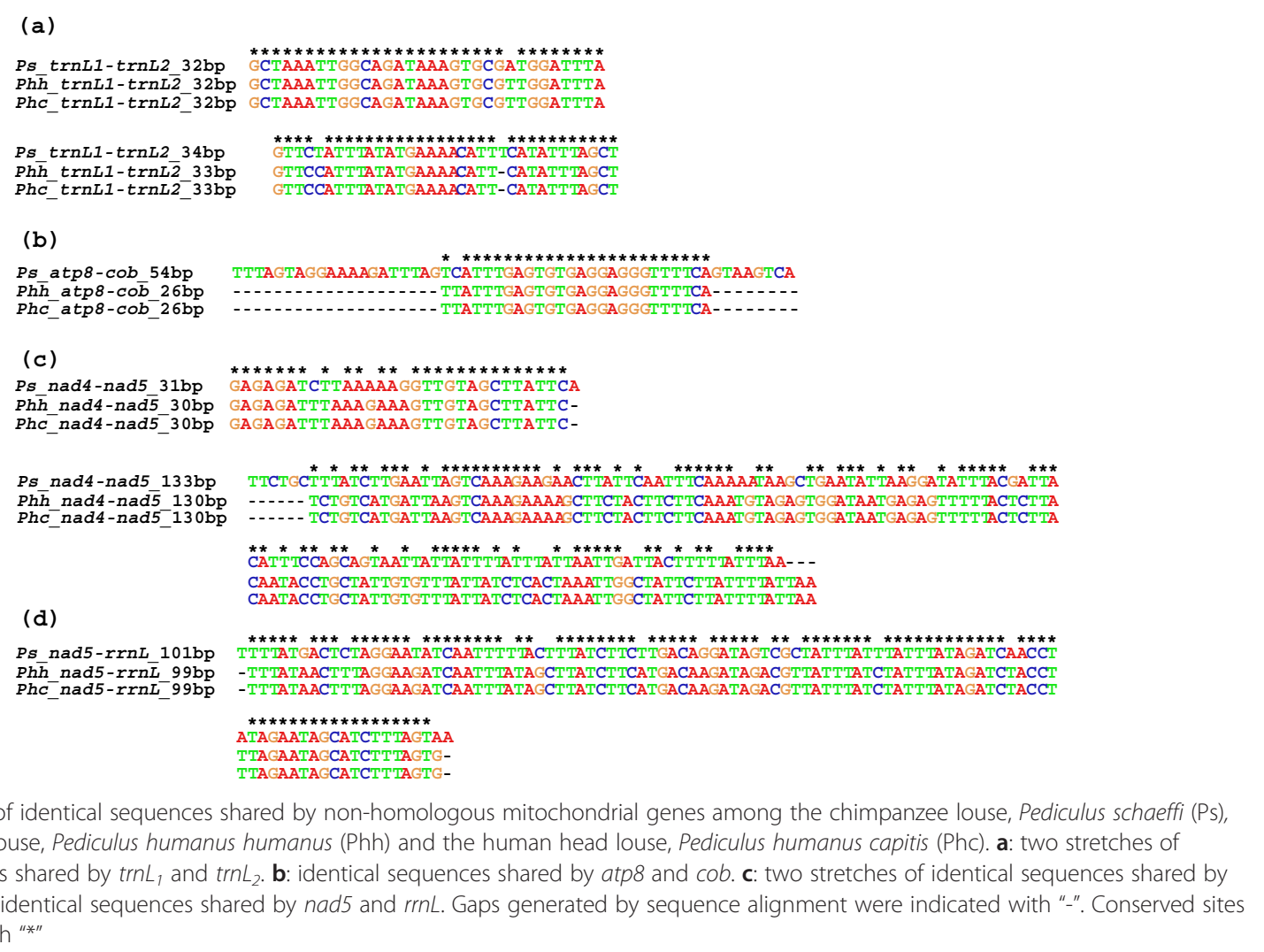

postulates a host-switch event of Pthirus lice from gorillas to humans, whereas the second hypothesis postulates a loss of Pediculus lice in gorillas and a loss of Pthirus lice in chimpanzees [14]. The first hypothesis is more parsimonious and assumes the coevolution of Pediculus lice with their hosts. Thus, the divergence between the human head louse and the human body louse on one hand, and the chimpanzee louse on the other hand, occurred at the time when their hosts, humans and chimpanzees, diverged 6 MYA ([1, 2], but see [3-5] for variation of the divergence time estimates).

Most bilateral animals have $37 \mathrm{mt}$ genes on a single circular chromosome, $15-20 \mathrm{~kb}$ in size [16, 17]. The human head louse and the human body louse, however, have their $37 \mathrm{mt}$ genes on 20 types of minichromosomes $[18,19]$. For the human pubic louse, the $34 \mathrm{mt}$ genes identified are on 14 minichromosomes [19]. We show in the present study that the chimpanzee louse has two less mt minichromosomes than the head louse and the body louse, although it is closely related to the human lice and is in the same genus Pediculus (Fig. 1).

The data available to date indicated that $\mathrm{mt}$ genomes already became fragmented in the most recent common ancestor (MRCA) of all blood-sucking lice (suborder Apoplura), as all of the species from both major clades of the sucking lice that have been properly examined have fragmented mt genomes [18, 19, 27-30]. Minicircles with mt genes were reported in a Damalinia species (Trichodectidae, Ischnocera), indicating that fragmented $\mathrm{mt}$ genomes may also be present in chewing lice [31]. The extensive fragmentation of $\mathrm{mt}$ genomes in the human head louse and the body louse $[18,19]$ and in the chimpanzee louse, however, does not appear to be an ancestral condition for sucking lice but a derived condition for the human lice and the chimp louse in the genus Pediculus since all other sucking lice studied to date have less or much less fragmented $\mathrm{mt}$ genomes than the human lice and the chimpanzee louse [18, 19, 27-30].

Among the 50 genera of sucking lice, Pediculus and Pthirus are most closely related to each other [7, 8, 14, 32, 33]. Pthirus species, thus, provide a proper outgroup for understanding mt genome fragmentation among the Pediculus species. Using the human pubic louse, Pt. pubis, as an outgroup for comparison (Fig. 4), we infer that: 1) the mt genome of the chimpanzee louse, which is less fragmented than that of the human head louse and the body louse, represents the ancestral condition for the genus Pediculus as the chimpanzee louse shares two gene arrangement characters, cob-trn $S_{1}$ and trnEtrnM, with Pt. pubis; and 2) the cob-trnS $S_{1}-\operatorname{trn} N$-trnE$\operatorname{trn} M$ minichromosome fragmented into three: one with cob, one with $\operatorname{trn} S_{1}$-trnN-trnE, and the other with $\operatorname{trn} M$ 


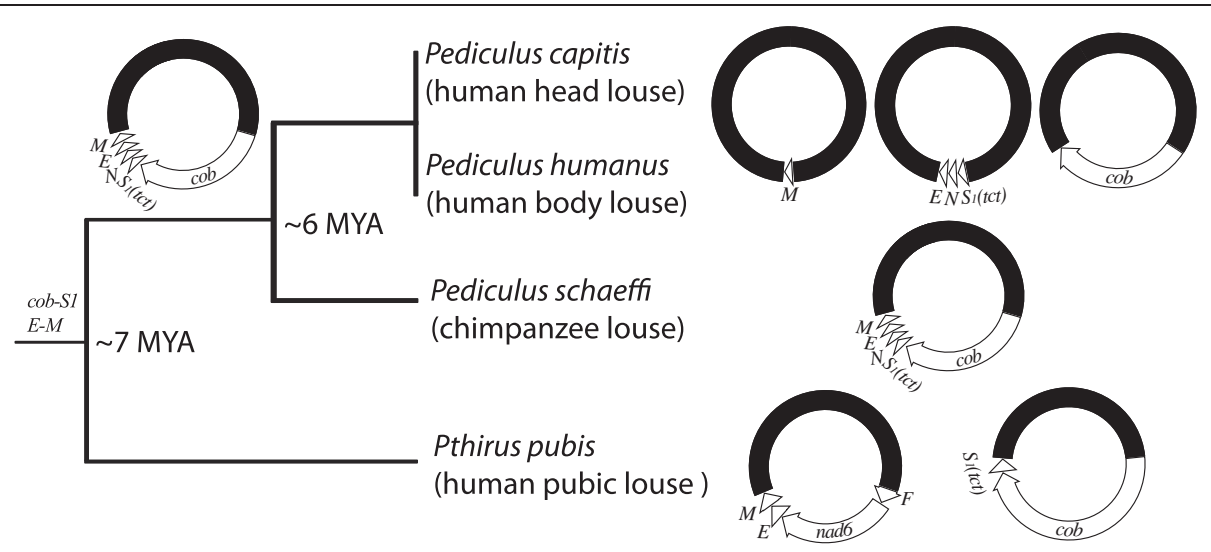

Fig. 4 Fragmentation of cob-trnS $S_{1}$-trnN-trnE-trnM minichromosome in the lineage leading to the human head louse, Pediculus capitis, and the human body louse, Pe. humanus. The split time, 6 MYA, for the chimpanzee louse from the human head louse and the body louse was after Goodman (1999) [1] and Glazko and Nei (2003) [2] for the chimpanzee-human split time. The split time, 7 MYA, for Pthirus pubis from the Pediculus species was also after Goodman (1999) [1] and Glazko and Nei (2003) [2] for the gorilla-(chimpanzee + human) split time

in the lineage leading to the human head louse and the body louse after this lineage split from that leading to the chimpanzee louse. Furthermore, it is likely that the cob-trnS $S_{1}$-trnN-trnE-trnM minichromosome fragmented into two minichromosomes first: one with $c o b$ and the other with $\operatorname{trn} S_{1}$-trnN-trnE-trnM. The latter then fragmented further into another two, generating the three minichromosomes we see in the human head louse and the human body louse today (Figs. 1 and 4). If this was the case, it would indicate that the fragmentation of one minichromosome into two took approximately $3 \mathrm{MY}$.

\section{Conclusions}

In conclusion, we sequenced the mt genome of the chimpanzee louse: the $37 \mathrm{mt}$ genes typical of bilateral animals are on 18 minichromosomes in this louse. Seventeen of the 18 minichromosomes of the chimpanzee louse have the same gene content and gene arrangement as their counterparts in the human head louse and the body louse. Five genes, $c o b, \operatorname{trn} S_{1}, \operatorname{trn} N$, $\operatorname{trn} E$ and $\operatorname{trn} M$, which are on three minichromosomes in the human head louse and the body louse, are on one minichromosome in the chimpanzee louse. Using the human pubic louse as an outgoup, we infer that a single minichromosome has fragmented into three in the lineage leading to the human head louse and the body louse since this lineage diverged from that leading to the chimpanzee louse 6 MYA when their hosts diverged. Our results provided insights into the process of $\mathrm{mt}$ genome fragmentation in the sucking lice in a relatively fine evolutionary scale.

\section{Availability of supporting data}

The nucleotide sequences of the $\mathrm{mt}$ genome of the chimpanzee louse supporting the results of this article have been deposited in GenBank (accession numbers KC241882-KC241897 and KR706168-KR706169). The mt genomes of the human body louse, head louse and pubic louse have been published previously (GenBank accession numbers: EU219983-EU219995, FJ499473FJ499490, FJ514591-FJ514599, HM241895-HM241898, and JX080388- JX080407) [18, 19].

\section{Additional files}

Additional file 1: Primers used to amplify and sequence the mitochondrial genome of the chimpanzee louse, Pediculus schaeffi. (DOC $101 \mathrm{~kb}$ )

Additional file 2: PCR amplicons from the mitochondrial genomes of the chimpanzee louse, Pediculus schaeffi. (DOC 105 kb)

Additional file 3: Alignment of the non-coding region sequences of the cox1, trnK-nad4, trnL-rrnS-C and trnL-rrnL minichromosomes of the chimpanzee louse, Pediculus schaeffi. (DOC 108 kb)

Additional file 4: The putative secondary structures of the 22 mitochondrial tRNAs of the chimpanzee louse, Pediculus schaeffi. (DOC 89 kb)

Additional file 5: The relative abundance between $\operatorname{trn} L_{1}(\operatorname{tag})$ and $\operatorname{trnL}_{2}($ taa) genes in the four minichromosomes that contain rrnS and $r r n L$ genes of the chimpanzee louse, Pediculus schaeffi, the human head louse, Pe. capitis, and the human body louse, Pe. humanus, revealed by Roche 454 sequencing. (DOC $101 \mathrm{~kb}$ )

\section{Abbreviations}

AGRF: Australian genome research facilities; atp6 and atp8: Genes for ATP synthase subunits 6 and 8; bp: Base pair; cob: Gene for cytochrome b; cox1, cox2 and cox3: Genes for cytochrome c oxidase subunits 1, 2 and 3;

DNA: Deoxyribonucleic acid; kb: Kilo base pair; $\mu \mathrm{l}$ : Microliter; $\mu \mathrm{M}$ : Micromolar; min: Minute; MRCA: Most recent common ancestor; mt: Mitochondrial; MYA: Million years ago; nad1, nad2, nad3, nad4, nad4L, nad5 and nad6: Mitochondrial genes for NADH dehydrogenase subunits $1-6$ and $4 \mathrm{~L}$; ORF: Open reading frame; PCR: Polymerase chain reaction; RNA: Ribonucleic acid; rRNA: Ribosomal RNA; rrns and rrnL: Genes for small and large subunits of ribosomal RNA; sec: Second; T: Thymine; tRNA: Transfer RNA; tRNA: Transfer RNA; trnA or A: tRNA gene for alanine; trnC or C: tRNA gene for cysteine; trnD or D: tRNA gene for aspartic acid; trnE or E: tRNA gene for glutamic acid; trnF or F: tRNA gene for phenylalanine; trnG or G: tRNA gene for glycine; $\operatorname{trnH}$ or $\mathrm{H}$ : tRNA gene for histidine; $\operatorname{trn} /$ or $\mathrm{l}$ : tRNA gene for isoleucine; $\operatorname{trnK}$ or $K$ : tRNA gene for lysine; $\operatorname{trn} L_{1}$ or $L_{1}$ : tRNA gene for leucine (anticodon NAG); $\operatorname{trn} L_{2}$ or $L_{2}$ : tRNA gene for leucine (anticodon YAA); trnM or $M$ : tRNA gene for methionine; $\operatorname{trnN}$ or $N$ : tRNA gene for asparagine; trnP or 
$P$ : tRNA gene for proline; trnQ or Q: tRNA gene for glutamine; $\operatorname{trnR}$ or $R$ : tRNA gene for arginine; $t r n S_{1}$ or $S_{1}$ : tRNA gene for serine (anticodon NCU); $t$ rnS $S_{2}$ or $S_{2}$ : tRNA gene for serine (anticodon NGA); $\operatorname{trnT}$ or T: tRNA gene for threonine; trnV or V: tRNA gene for valine; trnW or W: tRNA gene for tryptophan; trnY or Y: tRNA gene for tyrosine; A: Adenine; G: Guanine; C: Cytosine; T: Thymine; U: Uracil.

\section{Competing interests}

The authors declare that they have no competing interests.

\section{Authors' contributions}

RS and SCB designed the research. KEH and RS conducted the research and analyzed the data. KEH and RS wrote the manuscript. RS and SCB contributed reagents, materials and facilities. All authors approved the manuscript.

\section{Acknowledgements}

We thank Dr Natalie Leo, and Dr Rosa M. Garriga of the Tacugama Chimpanzee Sanctuary in Sierra Leone, for the chimpanzee louse samples. This work was supported by the Australian Research Council (DP0662755 to RS and DP120100240 to RS and SCB). RS also acknowledges the funding support for a group mission visit to China by the Australia-China Science \& Research Fund (ACSRF00980).

\section{Author details}

'Department of Parasitology, School of Chemistry and Molecular Biosciences, The University of Queensland, Brisbane, QLD, Australia. ${ }^{2}$ GeneCology Research Centre, Faculty of Science, Education and Engineering, University of the Sunshine Coast, Maroochydore, QLD, Australia.

\section{Received: 29 March 2015 Accepted: 14 August 2015}

\section{Published online: 03 September 2015}

\section{References}

1. Goodman M. The genomic record of Humankind's evolutionary roots. Am J Hum Genet. 1999;64:31-9.

2. Glazko GV, Nei M. Estimation of divergence times for major lineages of primate species. Mol Biol Evol. 2003;20:424-34.

3. Chen FC, Li WH. Genomic divergences between humans and other hominids and the effective population size of the common ancestor of humans and chimpanzees. Am J Hum Genet. 1999;68:444-56.

4. Stauffer RL, Walker A, Ryder OA, Lyons-Weiler M, Hedges SB. Human and ape molecular clocks and constraints on paleontological hypotheses. J Hered. 2001;92:469-74.

5. Langergraber KE, Prufer K, Rowney C, Boesch C, Crockford C, Fawcett K, et al. Generation times in wild chimpanzees and gorillas suggest earlier divergence times in great ape and human evolution. Proc Natl Acad Sci U S A. 2012;109:15716-21.

6. Zeng J, Konopka G, Hunt BG, Preuss TM, Geschwind D, Yi SV. Divergent whole-genome methylation maps of human and chimpanzee brains reveal epigenetic basis of human regulatory evolution. Am J Hum Genet. 2012;91:455-65.

7. Durden LA, Musser GG. The sucking lice (Insecta, Anoplura) of the world: a taxonomic checklist with records of mammalian hosts and geographical distributions. Bull Amer Mus Nat Hist. 1994;218:1-90.

8. Durden LA, Musser GG. The mammalian hosts of the sucking lice (Anoplura) of the world: a host-parasite list. Bull Soc Vector Ecol. 1994;19:130-68.

9. Kittler R, Kayser M, Stoneking M. Molecular evolution of Pediculus humanus and the origin of clothing. Curr Biol. 2003;13:1414-7.

10. Toups MA, Kitchen A, Light JE, Reed DL. Origin of clothing lice indicates early clothing use by anatomically modern humans in Africa. Mol Biol Evol. 2011;28:29-32

11. Yong Z, Fournier PE, Rydkina E, Raoult D. The geographical segregation of human lice preceded that of Pediculus humanus capitis and Pediculus humanus humanus. C R Biol. 2003;326:565-74.

12. Raoult $D$, Roux $V$. The body louse as a vector of reemerging human diseases. Clin Infect Dis. 1999;29:888-911.

13. Anderson AL, Chaney E. Pubic lice (Pthirus pubis): history, biology and treatment vs. knowledge and beliefs of US college students. Int J Environ Res Public Health. 2009;6:592-600.
14. Reed DL, Light JE, Allen JM, Kirchman JJ. Pair of lice lost or parasites regained: the evolutionary history of anthropoid primate lice. BMC Biol. 2007;5:7.

15. Light JE, Reed DL. Multigene analysis of phylogenetic relationships and divergence times of primate sucking lice (Pthirapter: Anoplura). Mol Phyolgenet Evol. 2009;50:376-90.

16. Boore JL. Animal mitochondrial genomes. Nucleic Acid Res. 1999;27:1767-80

17. Lavrov DV. Key transitions in animal evolution: a mitochondrial DNA perspective. Integr Comp Biol. 2007:47:734-43.

18. Shao R, Kirkness EF, Barker SC. The single mitochondrial chromosome typical of animals has evolved into 18 minichromosomes in the human body louse, Pediculus humanus. Genome Res. 2009;19:904-12.

19. Shao R, Zhu XQ, Barker SC, Herd K. Evolution of extensively fragmented mitochondrial genomes in the lice of humans. Genome Biol Evol. 2012;:1088-101.

20. Larkin MA, Blackshields G, Brown NP, Chenna R, McGettigan PA, McWilliam $H$, et al. (13 co-authors): Clustal W and Clustal X version 2.0. Bioinformatics. 2007;23:2947-8.

21. Kearse M, Moir R, Wilson A, Stones-Havas S, Cheung M, Sturrock S, et al. Geneious basic: an integrated and extendable desktop software platform for the organization and analysis of sequence data. Bioinformatics. 2012;28:1647-9.

22. Altschul SF, Gish W, Miller W, Myers EW, Lipman DJ. Basic local alignment search tool. J Mol Biol. 1990;215:403-10.

23. Schattner P, Brooks AN, Lowe TM. The tRNAscan-SE, snoscan and snoGPS web servers for the detection of tRNAs and snoRNAs. Nucleic Acids Res. 2005;33:w686-9.

24. Laslett D, Canbäck B. ARWEN, a program to detect tRNA genes in metazoan mitochondrial nucleotide sequences. Bioinformatics. 2008;24:172-5.

25. Bernt M, Donath A, Jühling F, Externbrink F, Florentz C, Fritzsch G, et al. MITOS: improved de novo metazoan mitochondrial genome annotation. Mol Phylogenet Evol. 2013;69:313-9.

26. Rice P, Longden I, Bleasby A. EMBOSS: The European molecular biology open software suite. Trends Genet. 2000;16:276-7.

27. Dong WG, Song S, Jin DC, Guo XG, Shao R. Fragmented mitochondrial genomes of the rat lice, Polyplax asiatica and Polyplax spinulosa: intra-genus variation in fragmentation pattern and a possible link between the extent of fragmentation and the length of life cycle. BMC Genomics. 2014;15:44.

28. Jiang HW, Barker SC, Shao R. Substantial variation in the extent of mitochondrial genome fragmentation among blood-sucking lice of mammals. Genome Biol Evol. 2013;5:1298-308.

29. Dong WG, Song S, Guo XG, Jin DC, Yang Q, Barker SC, et al. Fragmented mitochondrial genomes are present in both major clades of the blood-sucking lice (suborder Anoplura): evidence from two Hoplopleura rodent lice (family Hoplopleuridae). BMC Genomics. 2014;15:751.

30. Song S, Barker SC, Shao R. Variation in mitochondrial minichromosome composition between blood-sucking lice of the genus Haematopinus that infest horses and pigs. Parasites Vectors. 2014;7:144.

31. Cameron SL, Yoshizawa K, Mizukoshi A, Whiting MF, Johnson KP. Mitochondrial genome deletions and minicircles are common in lice (Insecta: Phthiraptera). BMC Genomics. 2011;12:394.

32. Barker SC, Whiting M, Johnson KP, Murrell A. Phylogeny of the lice (Insecta, Pthiraptera) inferred from small subunit rRNA. Zool Scr. 2003:32:407-14

33. Light JE, Smith VS, Allen JM, Durden LA, Reed DL. Evolutionary history of mammalian sucking lice (Pthiraptera: Anoplura). BMC Evol Biol. 2010;10:292. 